\title{
«০» Seminar.net
}

\section{The Digital Culture and "Peda-Socio" Transformation}

\author{
Kristen M. Snyder, Ph.D. \\ Department of Educational Science \\ Mid Sweden University \\ Kristen.snyder@miun.se
}

\begin{abstract}
This paper presents a concept called the digital culture, which emerged during a five-year research project of online professional development networks for educators. Turning first to a discussion about the digital culture model, I suggest that technology is no longer solely a separate, objective entity in society. The integration of technology in human communication engages technology as part of the communication act and therefore as part of the process of creating meaning. Developing an awareness of the implications for behavior, norms and values, and meaning making is integral to understanding the digital culture. Following a conceptual explanation of the digital culture model, I explore the implications for education, both in relation to opportunities and points of concern. My intent in this paper is to raise awareness and stimulate dialogue among educators about the need to see technology integrated with pedagogy, communication, and organizational systems. While considerable research has addressed dimensions of technology in learning and societal development, educational systems have yet to develop a holistic model that integrates all four. I suggest that this is a missed opportunity not only for schools, but also for engaging youth in lifelong learning and social transformation.
\end{abstract}

As an adult living in a technological age I find myself in something of a dilemma. As a participant in organizational and social life that utilizes email and SMS my life is certainly technologically oriented. But I feel like something of an outsider to a developing generation that has been born in and thoroughly baptized into a digital age for which technological immersion is the norm, access to information is increasing rapidly, the amount of information to which one needs to respond daily is at times overwhelming (for adults perhaps), and social networking is understood without even being discussed. While I recognize that my perspective predominantly represents life in the developed countries, the rate at which rural and underdeveloped communities around the world are gaining access is increasing daily. I observe these phenomena from the outside as an adult, as well as experiencing them from the inside, both culturally and organizationally, as email and SMS communication are increasingly institutionalized. As an educator interested in creating learning spaces for youth that are meaningful to human development, stimulating and contribute to the development of society, I am continually pressed with the question: why are we not learning from youth and integrating the digital culture in the school today? 
Statistics have shown for many years that keeping students stimulated in schools is tough. While the majority of youth succeed in the school systems around the world, there remains a substantial number who drop out for many reasons, including boredom. Survey results of 400 high school students in the U.S. showed that $89 \%$ of respondents found school itself to be somewhat or very boring (Shaw, 2004). Studies in adolescence and truancy report understimulation as one of the key variables in student dropout (Bridgeland, Dilulio, and Morison, 2006). Getting youth to school is often not the problem; keeping them there is. Compare this to a rapidly growing cyberculture in which youth are engaged daily in online activities with friends locally and globally. In fact, parents in many countries are now concerned with the amount of time students spend online (reflecting among other things family disengagement). Studies in Sweden report that each week 88 percent of Swedish youth aged 1520 are actively engaged in a cyber community, and this number is growing (Johansson, 2004). Among the activities of engagement are homepages, chat, podcasts, and email.

While studies are still examining the motivation for online behavior, initial findings suggest that the opportunity to create one's own identity and explore life with others is enticing. The ability to use one's own imagination and to develop questions of interest in dialogue with others empowers youth to take command of their own social relations and knowledge development. Similar cyber communities exist in other countries as well, including China, India, and Korea, and their function is on the rise. One study reports that in India, youth are using the Internet to worship, linking technology and religion (Majumder, 2007). The website serves as a host for religious services, making the practice of prayer and meditation more accessible to people who don't have time or access to large cities.

An even more encompassing recent development is Second Life, which is a $3 \mathrm{D}$ online digital world, "imagined, created and owned by its residents" (www.secondlife.com). The Second Life website, at the time of writing this paper, reports that $3,568,651$ residents participate in the digital world, which is characterized by new "creations", a marketplace, social networking, and a cyberdollar (Linden dollars) for economic transactions. Business Week Online (May 1, 2006) reports that Second Life, once characterized as a game, is really more akin to an alternative world, and as such "real-world" businesses are exploring questions about how a virtual system such as Second Life can "provide a template for getting work done, from training and collaboration to product design and marketing" (Business Week Online cover story, May 1, 2006).

Considering this reality of life outside the school, in which youth are actively and captivatingly engaged in social networks, creation, exploration, self empowerment and identity development, we begin to see that youth have both the motivation and the skills to connect and learn. A question that emerges then is what can schools do to adapt their learning environments, systems and curricula to build on the energy and opportunities of youth culture today that is already connected to societal development. I speculate that if we continue to develop schools only in relation to a model that focuses on academic or vocational achievement, we will lose more and more students to cyberland. One could certainly argue that cyberland has the potential to serve as a new community for those who don't like school, and in fact new research studies are examining the phenomenon of cyberland so as to better understand what motivates youth (Näslundh, 2003; 2005). The question I would like to pose is what would happen if schools connected the curriculum, teaching and learning to the culture of life in a technological age, building a digital culture in which youth are actively engaged in social learning networks through and with technology in collaboration with others. While the educational system often perpetuates a division between youth culture and academic learning, schooling would become much more stimulating and invigorating if the two were to 
connect. Furthermore, education would serve a major role in helping youth not only to develop identity through social networks but also to grapple with the emerging phenomenon of sensemaking, ethics, and perception that are changing with the integration of technology and human systems.

In this paper I would like to explore a concept called the digital culture, which emerged during a five-year research project of online social networks (Snyder, 2005; 2006), and the implications for educational development. I do not advocate a radical overhaul of educational traditions, nor do I wish to suggest that integrating technology, pedagogy, and human systems can serve the needs of all learners around the world at the present time. I do suggest, however, that given the trends in technological development, as well as its impact on social interaction, educators should explore the implications for learning and citizen development that goes beyond the classroom, building a foundation for lifelong learning, active citizenship, and social involvement.

Turning first to a discussion about the digital culture model, I will suggest that technology is no longer solely a separate, objective entity in society. The integration of technology in human communication engages technology as part of the communication act and therefore as part of the process of creating meaning. Developing an awareness of the implications for behavior, norms and values and meaning making is integral to understanding the digital culture. Following a conceptual explanation of the digital culture model, I would like to explore the implications for education, both in relation to opportunities and points of concern. My intent in this paper is to raise awareness and stimulate dialogue among educators about the need to see technology integrated with pedagogy, communication and organizational systems. While considerable research has addressed dimensions of technology in learning and societal development (much of which informs this argument), educational systems have yet to develop a holistic model that integrates all four. I suggest that this is a missed opportunity not only for schools, but also for engaging youth in lifelong learning and social transformation.

\section{Digital Culture: A conceptual framework}

The concept of the digital culture emerged from a five-year study of an international social learning network for educators (Snyder, 2005; 2006), in which a void was identified in the discussions and development of technology in education. Traditionally within the field of education, research has focused primarily on technology as a learning device, exploring developments in didactics and learning theory as they relate to classroom or online learning. While these contributions have been significant for expanding views about knowledge development and the importance of social dynamics in the learning environment, they have not addressed the development of social behaviors, norms, and values that cultural theorists suggest are being altered through interactions with technology.

As a culture theorist studying schools, it became evident to me that the focus of technology in education was too limited to achieve certain stated goals in educational policy that call for schools to prepare youth with skills and knowledge for working in the global knowledge society, including an orientation to lifelong learning, active citizenship, networking, entrepreneurship, and communication skills for understanding others (Field, 2000; Naval, Print, Veldhuis, 2002). Furthermore, the growing social development of youth in cyberspace communities potentially reinforces a divide between schooling and society as youth are creating alternative sources of connection and stimulation for learning and social networking that appear to mirror the very characteristics of living and working in the $21^{\text {st }}$ century. Seeing both the void and the growing divide raises questions about what schools can do to embrace a digital culture of learning that does not see 
technology as secondary to learning but rather as a co-creator in the learning environment for promoting both academic and social development.

Technology has taken on an integrated and integrating role in our socialhuman systems, which leads to new values, norms, and symbol systems that transcend the culture of nations and social groups (Lull, 2000). The digital culture is a reframing of the relationship between technology and humans, suggesting both dimensions are interchangeably subject and object within a cultural manifestation. This concept is embedded in cultural theory, which posits that culture is the shared values, assumptions, beliefs, rules and social practices that give rise to meaning and identity (Geertz, 1973; Lull, 2000; Schein, 1985). With reference to this definition, I suggest that technology has become an integrated part of our human communication system, and as such it is a constituent of the meaning-shaping process. Given the increasing global connection for learning and living today (Castells, 2000; Snyder, AckerHocevar, 2000), we need to ask ourselves in what ways are our perceptions, behaviors, values, and norms being shaped through our interactions with technology, and what are the implications when we consider technology in education from a social-cultural perspective of learning? Furthermore, what are the implications for education in the development of citizenship?

To understand this more fully, I turn to the constructivist notion (Berger, 1966) of sense-making and Weick's (1995) notion of sensemaking (intentionally spelled differently) as they both describe processes in which we, as humans, give meaning to identity, events, experiences, and encounters. Both concepts have elements that are relevant to understanding digital culture. Constructivist theory posits that we co-create our realities together, as we share and react to our perceptions and experience in response to situations. Through this co-construction we give meaning to our realities, resulting in common language, symbols, values, behaviors, norms, and understanding. As learners, we make sense out of our world by analyzing and synthesizing our experiences in an attempt to give meaning. The elements that contribute to our sense making process are those parts of an event or experience with and through which we interact and act. In contemporary society, technology and media have become a part of this social interaction process.

Weick's (1995) theory of sensemaking posits that as humans we are confronted by ambiguity and uncertainty in our daily encounters about which we must make sense. Through a series of stages characterized by "identity, social, retrospective, ongoing, enactment, and cues and plausibility" (p. 17), we give meaning to events and experiences, which become the process of sensemaking. $\mathrm{He}$ suggests that this is distinct from understanding, interpreting, or attributing, as those require a certain predetermined knowledge or framework in which to place information. The uniqueness of sensemaking then is that it takes place over time in response to patterns of experience, rather than in response to a predetermined knowledge framework. This theory has direct application to the digital culture, as we encounter daily ambiguities and uncertainties in our communication with and through technology that create the need for us to make sense out of our experiences. These ambiguities and uncertainties are stimulated by a variety of factors that characterize life in a digital culture today: technology, rapid information intake and synthesis, flexible and dynamic communities of exchange, asynchronous exchange, the broadening of perspective and experience with the expansion of our social communities, etc .

Referring to social constructivist theory and Weick's notion of sensemaking, I identify three key elements that are central to the digital culture argument. The first is that we, as humans, give meaning to experience, events, and encounters socially. In a growing world of connectivity and social networks we are connecting with a greater number of people across communities and cultures, expanding the type of encounter and experience in which we engage, 
as well the persons with whom we shape meaning. This has the potential to impact the kind of reality that we co-construct, as our social groups expand.

The second element is that this social construction takes place through the act of interacting with one another and our surroundings. As technology is central to human interaction today, it necessarily becomes a part of the act of communicating, and influences perceptions and behaviors. Studies from Reeves and Nass (1996) support this claim. They found that we treat computers like real people and places, suggesting that the way in which we receive a message is impacted by our relationship to the technology. In their studies they have shown that people tend to respond in a social manner to computers. For example, a negative attitude towards computers will affect the evaluation of a message received through the computer, no matter who the sender. The presence of technology in human communication is thus changing our behaviors and perceptions of one another, through which we socially construct a digital culture of meaning.

The third element relates to Weick's notion of ambiguity and uncertainty. As the tools of technology advance, our acts of communication are met with ambiguity and uncertainty, causing us to ask new questions about how can we understand one another. The old frameworks for understanding human communication, based on knowing how to interpret verbal and non-verbal cues, are no longer helpful in much of our exchanges today that are characterized by text-based messages and asynchronous exchange. We are now faced with the ambiguities and uncertainties of how to interpret one another, placing us in a space of what Weick calls: sensemaking.

When we consider Weick's (1995) concept of sensemaking and constructivist theory in the context of our use of technology in human interaction, it is possible to see the way in which digital media are not only integrated into our daily lives, but have also become a layer in our culture and in the meaning making process. In an earlier paper (Snyder, 2005), I suggested that:

No longer are we living in an era where "online communication" is a separate phenomenon from our daily lives. It now permeates our organizational walls and human systems to create a digital culture, which is reflected by the integration of technology in everyday life such that our human systems of interaction and work transpire in a physical and virtual space interchangeably (Snyder, 2005; 7).

The message is that the place of technology in our lives and its role in connecting humans also contribute to the process of shaping meaning. This is in contrast to the technological determinist (Chandler, 1995) theory that suggests that technology drives development, and that we as humans do not participate in shaping its purpose or function in society. Contrary to this view, I suggest that not only do we as humans shape our realities through interaction with our surrounding context, but that elements, such as technology, also take on new meaning and become a part of the culture, shaping it and being shaped by it. In an earlier work (Snyder, 2005), I argued that Mcluhan's (1964) notion of the "medium is the message" is powerful, albeit unidirectional: it omits the interaction that now exists between humans and technology through which we communicate. Radio and TV (as in McLuhan's examples) address a unidirectional relationship of sending and receiving, in which case meaning making takes place in a separate act disengaged from the technology. In contrast today, with the current advances in communication technology, the media have become a part of the sense making equation, thus calling for an interactive perspective (Denzin, 1992), rather than a deterministic view.

Using culture theory as a lens, I would like to illustrate ways in which the presence of technology in our human communication systems is altering our 
behaviors, challenging social norms and expectations, and contributing to the development of our perceptions. As a cultural dimension, technology has taken on a value-laden symbol and role as connector. Those who are "connected" are perceived differently from those who are not. We see this both at the global level, and at the human user level. At the global level, the spread of communication technology was initially hailed as a potential stimulus for bringing about greater equity among nations and cultures around the world (Castells, 1996). Many countries within the European Union developed a 10year plan to provide connectivity to every household and community in EU countries. Ten years later, such plans have brought about considerable change, as many more persons and cultures are connected. Yet there still remain areas in countries (i.e., villages in China, Sweden, Russia, and Africa) where connectivity is non-existent. Consequently, the world is witnessing a new set of inequities, economically and socially brought about by the quest and promises of connectivity (Capra, 2002; Castells, 2000; Friedman, 2005).

At the institutional level the value of connection has led to new assumptions and codes of conduct in both human communication as well as work production. In the initial years of technology in the workplace, value was given to our "ability to use" technology; today the value is on "ourselves as users". Not only are we expected to know how to use a computer and the appropriate software, it is anticipated in many settings and countries that we are comfortable communicating through email and virtual platforms, and accessing and working with information storage and sharing systems. The assumption is that technology is no longer an external tool to our human interactions, but an integrated dimension of working and living in the $21^{\text {st }}$ century.

On the one hand, the value of connection is opening new models of work and knowledge development, built on networks (Stephenson, 2005). On the other hand it is amputating our ability to be fully present in many of our human exchanges, both in formal settings as well as the informal social settings of family life. In places of business and schools, for example, the presence of the telephone is so common that we don't even blink twice when our meetings are interrupted by a telephone call or students SMS their friends (we can be frustrated, but not surprised). In organizations where wireless connections are made possible, many people take their computers to meetings and remain connected online while they also engage in the face-to-face meeting. In addition, for those working in virtual organizations, it is not uncommon for the stationary phone to ring (and be answered) while they are participating in a web-cast meeting. In the context of family, Bakardjieva, (2005) found that computers are altering family dynamics and parenting in dramatic ways. With access to "everything" through the Internet, youth are spending more time online than with family. They are still at home, yet absent. The impact of our connections through technology today is great for it both extends us and amputates us. On the one hand, the ability to get work done wherever we are and to stay connected contributes to an energy and productivity for those engaged. For those on the outside of the connection, perception can develop about how they are valued by others, reinforcing technology over human aspects, which impacts our perceptions, social dynamics and emotions.

Another phenomenon that emerges from the need to be connected is "information overload", which is leading to new behaviors of retreat and hiding for some, and task overload for others. With the 24/7 exchange of information, instant messaging, and emails, finding time to complete intended tasks is difficult as the definition of work shifts focus to "reading and replying to email" or "answering the mobile telephone". In some cases, people are taking it upon themselves to develop new work habits, either setting aside a specific time to respond to email or phone calls, or just completely ignoring emails altogether because they take too much time away from the intended work. The new, emerging codes of conduct are not yet institutionalized, and as 
such are shaping people's perceptions of information and one another. Human communication and sensemaking are impacted as some people "switch off", while others sit waiting.

The speed of connection and information exchange also contributes to changing perceptions, behaviors, and expectations. Without thinking, we have developed a social dynamic in which we often "assume" that a person will respond to us immediately as we have become so ingrained in the "instant response" capability of technology. As technology and human action become integrated, we no longer associate "instantaneous" with the technology, but rather with the human act of communication. When the response isn't immediate or as anticipated we often begin to speculate why. Sometimes we speculate falsely leading to new actions based on something that doesn't exist. We perceive that because the person has the technology at their disposal they should be available for open communication "when we need them". Our changing perception alters social dynamics, as well as the communication exchange shaping sensemaking.

Among youth this is quite prevalent and also problematic as technology is adding to stress and addiction with the need to stay connected and always available. The Östersund Post reported recently an increase in adolescent stress caused by youth sleeping with their telephones turned on so they don't miss calls in the middle of the night. During school time they stay connected with friends through SMS. An Australian study (Australian Youth Facts and Stats, 2005) reported that more than one-third of Australians age 14-24 cannot live without a mobile phone. And Lonkila (2004) found that mobile phones are increasing our connectivity and the strength of our social networks, "impacting the very nature of sociability" (p. 59). Whether it is the computer and connections to the Internet or the mobile telephone, our need to be connected and available $24 / 7$ has become a norm and value in our global society.

As a last example, I would like to address power. Power is a complex phenomenon in any social culture. How it is shaped, defined, and used can differ from group to group, resulting in very different cultures. Within a digital culture, perceptions of power are emerging that result from a number of factors, including our personal relationship to technology (Reeves and Nass, 1996), our perceptions of the written word (Ramberg, 1996), and how digital communications are used to include or exclude members of a work environment. These elements are adding a new dimension to existing power structures in some cases, and in others giving rise to new perceptions of power bases and, consequently, to the ways in which communication is mediated by technology. Studies (Reeves and Nass, 1996) have shown that technology itself has a perceived power, and that those who use it obtain a kind of power over others in some organizational settings. In this case it can matter who is sending, as well who isn't sending. Further, it can matter who is included and who is excluded. In some organizations and social groups, email, for example, can be used to privilege the sender, giving them a perceived power. This can be achieved by sending emails to only a few, creating an "in" group and an "out" group. Power can thus also be perceived by the way in which the digital dialogue takes shape. If only a few recipients of a group email, for example, respond and continue to engage in the dialogue, they build a power-base that eventually can exclude those who don't participate. In such a case, it becomes critical to understand the reasons why only certain people respond: time, role, expectations, or knowledge. Digital communication has the power to reinforce existing power structures or invite collaboration.

In addition to our own relationship to technology, perceptions of power are affected by how we perceive the written word (Reeves and Nass, 1996). When we receive an email, we perceive the text and the computer to be THE communicator. In order to see the sender (and hold in perspective the power 
of the message) we are required to envision or fantasize beyond the text and the technology to the person. It is in this space that we often stop short of the fantasizing and relegate the text and computer to a higher position in the communication than the sender. Depending on our relationship to text and technology, as Reeves and Nass (1996) suggest, our perception is altered and so is our sensemaking, for it is often our actions with technology that we hold first and foremost. Connecting this with the growing use of emoticons and acronyms as a language system of communication and sensemaking, we might ask ourselves the ways in which our communication is changing our perceptions, giving rise to an unintended social order.

These are but a few examples of the ways in which technology plays a key role in contributing to a new culture of social interaction which influences our perceptions and sense making. In an era when knowledge development is perceived as social and networking is more and more the structure for working, living, and learning, new questions arise about the need for a holistic understanding that integrates technology in the sensemaking and knowledge development process. Seen once as an external tool, technology is now an integrated artifact in our cultures and a part of our processes of shaping meaning, perceptions, behaviors, norms, and values. So what does this have to do with education? I believe there are two primary dimensions to consider and they relate to the pedagogical and sociological responsibility and context of schooling today. There are a number of questions raised about the pedagogical practices in schools because changes in society as they relate to a higher value placed on knowledge development and human capital, the ability to network and be entrepreneurial are raising questions about the pedagogical practices in schools for citizenship preparation. Moreover, the need for a digital literacy in which one can use technology for communication and work reinforces not only our technological know-how, but also an awareness of and social responsibility towards using technology to promote human equity and sustainable societal development. While advances in technology have opened the door to the kinds of changes we are witnessing in society, it is the social dimension that has become so critical, calling upon education to play a role in helping develop citizens with the skills necessary to interact in a global and local context.

The premise of the digital culture is to suggest that we as a society, including our social institutions, have a responsibility to understand the process of sensemaking in general, as this becomes a more complex phenomenon in a multi-cultural landscape. Moreover, as our human connections are conducted more and more with and through technology, we need to understand what is happening to our perceptions, norms, values, behaviors, and customs as these all relate to the ways in which we shape meaning. For schools the challenge is how to embrace a digital culture that cares for both the pedagogical task of education, as well as the social development of citizenry, which includes an understanding of the implications for knowledge development and sensmaking. Through the digital culture then, education can contribute to both a pedagogical and sociological development, which I refer to as "peda-socio" transformation.

\section{The Digital Culture and Education}

The current rhetoric, policy, and programming models in education are calling for a focus on lifelong learning, entrepreneurship, networking, digital literacy and active citizenship. To this end, a number of key competencies for success in life and the workforce have been developed. Rychen and Salganik (2003) categorized the key competencies for successful life and a well-functioning society into three broad areas: 1) interacting in socially heterogeneous groups, 2) acting autonomously, and 3) using tools interactively. The European Commission on Education (2004) refers to the knowledge worker, with skills in networking, entrepreneurship, lifelong learning, and active citizenship. 
Thomas Friedman's (2005) theory that the world is flat suggests the need for workers to be prepared for a new business model built on in-sourcing, outsourcing, networking, collaboration, and open sourcing and digital living. Also emerging are concerns about human caring and social engagement that have led to a plethora of arguments for developing skills in dialogue, collaboration, appreciative inquiry, caring, and spirituality (Bohm, 1996; 2004; Brown and Isaacs, 2005; Nodding, 1991; 2002; Russell, 1998; Wells and Claxton, 2002). In 2004, The European Union Commission on Education identified eight key competencies that should underpin education in the $21^{\text {st }}$ century, of which "digital competence" is one. They state that "ICT skills comprise the use of multi-media technology to retrieve, assess, store, produce, present and exchange information, and communicate and participate in networks via the Internet” (p. 22). Included in the equation now is the social dimension, reflecting a pedagogical shift from individual learning to a socialcultural model (Claxton, 2002; Wells and Claxton, 2002).

The stimulus for the above competencies and focus on networking and lifelong learning stems from advances in technology and changes in organizational, economic, and national systems. In 1996 Manual Castells (1996) awakened us to the concept that we were "living in the network society". His basic message was that the growth in technology would create possibilities for people to connect within and across cultures, anticipating advances in democracy, solidarity and peace around the world. While later observations (Castells, 2000) have shown that this has not happened yet, the network society did lead to the expansion and significance of social networks in shaping global transformation. Capra (2002) states that, "in the information age, networking has emerged as a critical form of organization in all sections of society. Dominant social functions are increasingly organized around networks, and participation in these networks is a critical source of power" (p. 149). With the use of the internet, blogs, FAQ pages, and chatrooms, video conferencing and asynchronous conferencing systems, for example, we have upped the ante on the power of social networks for global transformation through knowledge exchange. Thomas Friedman (2005) posits that, "we are now connecting all the knowledge centers on the planet together into a single global network, which-if politics and terrorism do not get in the way-could usher in an amazing era of prosperity" (p. 8).

Central to pedagogical development in the changing society are social learning networks (Köhler, 2004; Stephenson, 2005), which through technology have an important role in developing global citizenship and engaging education in societal transformation. In a digital culture, social networks engage educators and youth in global communities of practice (Wenger, et. al. 2002) based on collaborative learning (Soresen and Tackle (2002). Curriculum is generated through human exchange in response to social conditions, rather than from a set of governmental standards derived from a model of measurement and competition. Lave and Wenger (1991) suggest that where learning is concerned, community creates the curriculum and that the conditions for effective learning appear to be related to our direct engagement in community. Together, these elements create a pedagogy of engagement in a digital culture that has the potential to help youth meet the key competencies for lifelong learning and sustainable development in the knowledge age.

Contrasting this with the dominant pedagogical model found in most schools today, there is a vast divide between k-12 education and preparation for living, working and lifelong learning. Recent studies examining technology in schools (Fredriksson, et al., 2006) demonstrated that most of the innovations related to ICT in schools have not impacted pedagogical or school development. The dominant model based on individual psychology has yet to be replaced with a pedagogy based on the socio-cultural. It is not until we come to the higher education level and professional development that we witness learning models that are reflective of the social context of living and work today. In fact, the 
majority of research on learning communities and online learning has been conducted at the college and university level.

So what then can educators do to respond? I suggest that there are four key components that can frame advances in education and ultimately develop a platform for lifelong learning at a young age. The four components are: technology, pedagogy, communication and organizational systems. The premise is that by integrating the four, rather than holding them as separate aspects of education, learning can become a dynamic process in which youth are engaged in social networks and communities of practice, shaping their own knowledge in relation and response to society and the workforce. At the heart of the interaction is the digital culture of sensemaking that emerges through human interactions with one another in the presence of technology.

Figure 1 illustrates the four elements, which intersect with one another to shape a digital culture of sensemaking. For example, technology is used for communication and learning (pedagogy), which impacts the role of the student, the teacher, views of knowledge and learning. Technology is developed to meet learning needs and capacities, which extend both human communication and technology. The organization of learning and the educational institution in relation to scheduling, resource allocation, use of space, teaching models and the organization of the curriculum are all impacted.

DIGITAL CULTURE

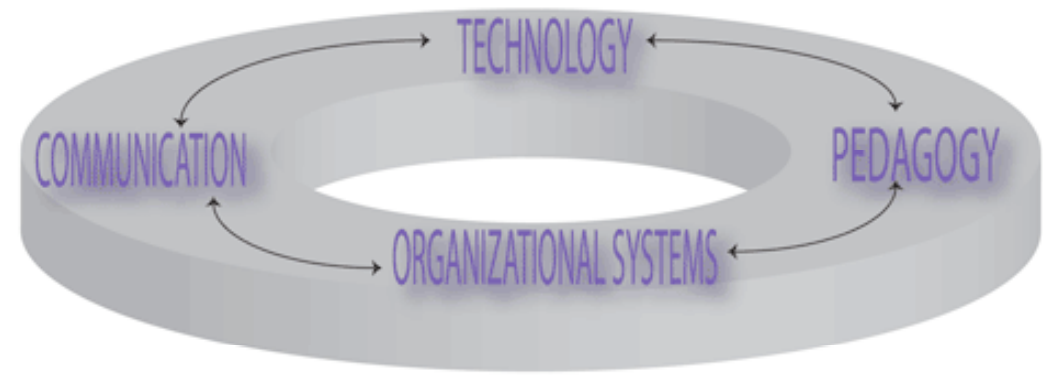

PHYSICAL

VIRTUAL

Figure 1

To understand this in practice, I suggest the need for educators to explore the development of knowledge and the focus on social connections. It is important to see knowledge in a broad context that contributes not only to economic growth and development, but also to social and human caring. Further, educators need to understand what kinds of technology are available today (all forms of media, internet, blogs, podcasts, Second Life, virtual communities, web-based conferencing systems, etc) and how they can be used to facilitate and stimulate learning. It is also important to recognize the need to create a culture of learning at all levels of the school to facilitate lifelong learning and the continual advancement of pedagogy in response to societal growth (Snyder, Acker-Hocevar, Snyder, 2000). According to Tuckett (1997) "at the heart of the learning society are learners and potential learners and the communities in which we live" (p. 24). Table 1 highlights a few of the dimensions available or present in schools today that can be further developed in relation the digital culture for "peda-socio" development. 


\begin{tabular}{|c|c|c|}
\hline Global Learning Context & $\begin{array}{c}\text { Technological Context } \\
\text { of learning }\end{array}$ & $\begin{array}{c}\text { Knowledge } \\
\text { development in the } \\
\text { global age }\end{array}$ \\
\hline $\begin{array}{l}\text { - } \text { Active citizenship } \\
\text { - } \text { Digital literacy } \\
\text { - } \text { Networker } \\
\text { - } \text { Mutrepreneurial } \\
\text { - } \text { Team work } \\
\text { - } \text { Collaborative/collaboration } \\
\text { (?) } \\
\text { - Value for humanity and the } \\
\text { - Cnvironment } \\
\text { - Cultural heritage }\end{array}$ & $\begin{array}{l}\text { - } \text { Communication online } \\
\text { - } \text { Social learning } \\
\text { networks } \\
\text { - } \text { Collaborative learning } \\
\text { - Role relationships } \\
\text { - } \text { Multi-media } \\
\text { - } \text { Asynchronous } \\
\text { conference systems } \\
\text { Portfolio systems for } \\
\text { assessment }\end{array}$ & $\begin{array}{l}\text { - Social constructivism } \\
\text { - Social collaborative } \\
\text { learning versus } \\
\text { Individual learning } \\
\text { - Knowledge } \\
\text { acquisition versus } \\
\text { knowledge } \\
\text { development } \\
\text { - Self-directed learning } \\
\text { - Real-world based } \\
\text { curriculum }\end{array}$ \\
\hline
\end{tabular}

Table 1: Dimensions of Pedagogy in the Digital Culture

Referring to elements from Table 1 , I offer an example: Take as a starting point the fact that many youth spend their evenings online, in chat forums, interacting with blogs and making their own podcasts, etc. Their world is reflected in the three dimensions of Table 1: Global learning context, technological context of learning and knowledge development through social interaction. What could happen to learning environments in schools if they engaged the cyberworld of youth in the classroom? This could include letting youth build their own social networks of learning in the school and across schools, through which they work together to develop a collective curriculum. The work of the teacher then is not to decide what and how students should learn, but rather to facilitate learning and growth in relation to a social curriculum, focusing on issues of democracy, ethics, values, reading, writing, math, and so forth. Further, teachers have an opportunity to help facilitate awareness among youth about how the digital culture in which they are engaged shapes their perceptions, norms, behaviors, and expectations of one another as a way to develop citizenship. The basics of schooling need not change; the question is from where does the curriculum develop and what role do students have in the development process?

If we return to the examples of connectivity, speed, information overload, and power mentioned earlier in the paper, to what extent are teachers using such scenarios as learning opportunities? Currently in Sweden, for example, there is a move to legalize the rights of teachers to remove mobile phones from students in schools. While this is certainly one model of responding to the effects of technology in our social systems, one might also ask what learning opportunities are being missed. In what ways could teachers, instead, help youth explore implications about technology for themselves in order to be a part of shaping a responsible and creative digital culture of learning and living in the future? As adults, we may not have the degree of technological savvy that lies in youth, but we do have the historical experience and awareness from which to raise new questions about social and human dynamics in a digital culture.

\section{Conclusions}

In this paper I have put forth a thesis to suggest that there is more to technology in education than meets the eye. The current efforts in schools show little innovation, reflecting a sense that if we just put a computer in the classroom, schools have somehow integrated technology into education. A few years ago a principal of a school said to me, "our students are living in another world than we as adults. It is our job as educators to learn from them about how to develop the future school". His words came in the late 1990s before virtual communities were popular among youth, yet he was able to see that what youth were doing already with technology was far more advanced than 
how educators were thinking. In many ways this divide has only continued to grow, and now researchers are beginning to study the phenomenon of the cyberworld in the hope of understanding more about motivational theory to engage students in schools. As students' after-school world expands rapidly with social connections and whole new virtual worlds of identity and meeting places, schools fall farther behind in their ability to capture the attention of youth. It is in this space that I believe schools have both an opportunity and a responsibility. The opportunity arises from the possibility to build learning environments based on the social, communication and technological aspects found in society today. The responsibility relates to developing awareness about the impact on sensemaking in a digital culture.

With the growing challenge and public demand for schools to foster future citizens in the information age, educators have a natural context in which to expand and transform their knowledge and understanding of the relationship between humans and technology from a variety of perspectives. Building a digital culture in schools implies that educators use a range of multi-media to facilitate learning in a social context, in which youth are networked interculturally, and where the global community informs the curriculum. Youth of today need to learn in a context that mirrors the society they already know so well, which is based on connections, networking, rapid rates of high-volume information, and a changing cultural landscape. Moreover, educators who see themselves as members of the digital culture, interconnected in their own social networks of learning and knowledge development, can assure a pedagogy that is responsive to changing societal conditions. The digital culture is one in which we are all members, connected in a variety of communities of practice (Wenger, et. al., 2002) shaping society and culture.

Such a pedagogical shift necessarily recognizes the integration of technology in our lives and its impact on our human connections and learning. Shaping a digital culture of learning in the global age is about more than technological innovations in schools. It is about creating a working culture in which staff and students engage in shaping their own learning and social development. Borrowing from the fields of culture and communication studies, we are reminded that as learners we are not just students in a classroom following a curriculum. We are members of a larger culture that becomes our curriculum. As we engage with one another in active exchange, we give meaning to a collective space. Using media and technologies contributes to our communication, giving rise to new knowledge to shape a global ecumene. Educators have the possibility to take the next step and support the development of schools as living systems, not just bureaucratic institutions. As living systems, composed of cultures and networks, schools can adapt their learning environments to respond to changes in society and prepare youth for lifelong learning and living in a global age.

\section{Biographical description}

Kristen Snyder is senior faculty at the department of educational sciences at Mid Sweden University. Her research focuses on school and leadership development in a global age, with specific emphasis on social networks for learning and professional development and the digital culture. She is the author of numerous publications, including the co-authored book: Living on the edge of chaos: Leading schools into the $21^{\text {st }}$ century. 


\section{References}

Australian Youth Facts and Stats (2005). Media and Entertainment. Online statistics published by Australian Clearinghouse for Youth Studies. http://www.youthfacts.com.au/index.php?option=displaypage\&Itemid=261\&op =page Downloaded November 4, 2006.

Bakardjieva, M. (2005) Internet society: the internet and everday life. London: Sage Publication

Berger, P. (1966) The social construction of reality. Garden City; Doubleday.

Bohm, D. (1996) On Dialogue. New York: Routledge Press

Bridgeland, J. M., Dilulio, J., Morison, K. B. (2006) The silent epidemic: Perspectives of high school dropouts. A report of the Civic Enterprises in association with Peter D. Hart Research Associates for the Bill and Melinda Gates Foundation. March 2006. http://www.civicenterprises.net/pdfs/thesilentepidemic3-06.pdf

Brown, J., Isaacs, D. (2005) The World Café: Shaping our future through conversations that matter. San Francisco: Berrett-Kohler.

Businessweek Online (2006) My Virtual Life: A journey into a place in cyberspace where thousands of people have imaginary lives. Some even make a good living. Big advertisers are taking notice. May 1, 2006. http://www.businessweek.com/magazine/content/o6 18/b3982001.htm

Downloaded February 9, 2007.

Capra, F. (2002) The hidden connections. Integrating the biological, cognitive, and social dimensions of life into a science of sustainability. New York: Doubleday

Castells, M. (1996; 2000) The Network Society. second edition. Oxford: Blackwell Publishers

Chandler, Daniel (1995): 'Technological or Media Determinism' http://www.aber.ac.uk/media/Documents/tecdet/tecdet.html. Downloaded January 29, 2007.

Denzin, N. K. (1992) Symbolic interactionism and culture studies: The politics of interpretation. Cambridge, MA: Blackwell Publishers.

European Commission. (2004). Implementation of "Education and Training 2010" Work Programme. Brussels: European Commission, Directorate General for Education and Culture.

Field J., (2000) Lifelong learning and the new educational order. London: Trantham Books

Fredriksson, U., Plomp, T., Jedeskog, G., Sorensen, E., Rasmusson, M. (2006) Innovative use of ICT in schools in Denmark, Norway, Sweden, Germany, Portugal and the United Kingdom. Paper presented at the NERA Annual conference, 9-11 March, Örebro, Sweden.

Friedman, T. (2005) The world is flat. New York: Farrar, Straus and Giroux.

Geertz, C. (1973) The interpretation of cultures. Basic Books: A division of HarperCollins Publishers.

Johansson, E. (2004) Hur söka unga sin identitet på Lunarstrom? Forskningsnyheter: Karlstad Universitet. http://www.kau.se/forskning/nyheter/artikel.lasso?artikel id=3372\&show=for skning\&search word. Downloaded February 9, 2007. 
Köhler, B. (2004) Weak ties, modern epidemics and world society. Connections. 26(1): 9-10

Lave and Wenger, 1991 Situated learning: Legitimate peripheral participation. Cambridge, UK: Cambridge University Press.

Lonkila, M. (2004) Phone notebooks as data on personal networks. Connections. 26 (1): $53-61$

Lull, J. (2000) Media, communication , culture: A global approach. Cambridge: Polity Press in association with Blackwell Publishers.

Majumder, S. (2007) India's youth hit the web to worship. BBC News, Madras. february 8, 2007.

http://newsvote.bbc.co.uk/mpapps/pagetools/print/news.bbc.co.uk/1/hi/world/south asia/6322237.stm. Downloaded February 9, 2007

McLuhan, M. (1964) Understanding media. London: Routledge Classics.

Naval, C., Print, M., Veldhuis, R (2002) Education for democratic citizenship in the new Europe: context and reform. European Journal of Education, 37 (2), 10728

Näslundh, C. (2005) Chattspråk och SMS på väg in i skriftspråket. Forskningsrapport: KK Stiftelsen Kollegiet. Downloaded februari 7, 2007. http://www.kollegiet.com/templates/StandardPage.aspx?id=2102\&mode=print

Noddings, Nel (2002) Starting at Home. Caring and social policy, Berkeley: University of California

Noddings, N. (1991) Stories in dialogue: caring and interpersonal reason. In Witherell, Carol, and Nel Noddings. Stories lives tell : narrative and dialogue in education. New York: Teachers College Press.

Näslundh, C. (2003) Lunarstorm har inget med datorer att göra. Forskningsrapport: KK Stiftelsen Kollegiet. Downloaded February 7, 2007. http://www.kollegiet.com/templates/StandardPage.aspx?id=354\&mode=print

Ramberg, R. (1996) Psychological aspects of explanations as support for problem solving and learning. Stockholm: Stockholm Universitet.

Reeves, B, Nass, C. (1996). The media equation : how people treat computers, television, and new media like real people and places. Cambridge : Cambridge Univ. Press

Russell, P. (1998) Waking up in time: Finding inner peace in times of accelerating change. Novato, California: Origin Press.

Rychen, D. S., Salganik, L. H. (2003) Key competencies for a successful life and a well functioning society. Göttingen, Germany: Hogrefe and Huber.

Schein, E. (1985) Organizational culture and leadership. San Francisco: Jossey-Bass.

Second life website. Downloaded February 9, 2007 http://secondlife.com/

Shaw, James (2004) Center for Youth Studies: Boredom. webdocument: http://roswellga.ourlittle.net/Boredom. Dowloaded February 9, 2007

Snyder, K. (2006). Stimulating dialogue online in cross cultural learning communities, in Technological Aspects of Mentoring, F. Kochran, J. Pascarelli (eds) Infomage Press.

Snyder, K. M., (2005) The digital culture and communication: More than just classroom learning. Seminar.net: Media, Technology, and Lifelong Learning. vol 1 issue 2: (www.seminar.net) 
Snyder, K. J., Acker-hocevar, M., Snyder, K. M. (2000)Living on the edge of chaos: Leading schools into the global age. Milwaukee, WI: ASQ: A Quality Press.

Sorensen, E.K., \& Takle, E.S. (2002). Collaborative knowledge building in web-based learning: Assessing the quality of dialogue. International Journal of E-learning, 1 (1), 28-32.

Stephenson, K. (2005) Trafficking in Trust: The Art and Science of Human Knowledge Networks in : Enlightened power : how women are transforming the practice of leadership, ed. L. Coughlin, E. Wingard, and K. Hollihan (San Francisco : Jossey-Bass, c2005) pp. 242-265

Tuckett, A. (1997) Lifelong learning in England and Wales. National Institute of Adult Continuing Education, Leicester.

Weick, K. (1995) Sensemaking in organizations. Thousand Oaks: Sage Publications

Wells, G. Claxton, G. (2002) Introduction: Sociocultural perspectives on the future of education. In. Gordon Wells and Guy Claxton (eds) Learning for life in the $21^{\text {st }}$ century: Sociocultural perspectives on the future of education. Oxford: Blackwell Publishers. 